\title{
Molybdenum-Catalyzed Synthesis of Nitrogenated Polyheterocycles from Nitroarenes and Glycols with Reuse of Waste Reduction By-product
}

\author{
Rubén Rubio-Presa, M. Remedios Pedrosa, Manuel A. Fernández-Rodríguez, Francisco J. \\ Arnáiz, and Roberto Sanz* \\ Departamento de Química, Facultad de Ciencias, Universidad de Burgos, Pza. Misael Bañuelos s/n, 09001-Burgos, Spain \\ Supporting Information Placeholder
}

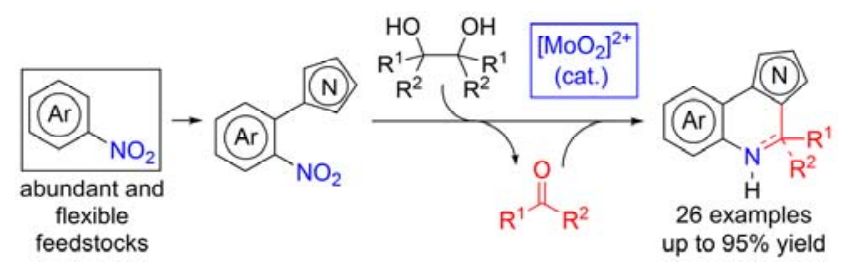

ABSTRACT: A novel domino reduction/imine formation/intramolecular cyclization/oxidation for the efficient synthesis of
pyrrolo(indolo)[1,2-a]quinoxalines and pyrrolo(indolo)[3,2-c]-quinolines from readily available nitrobenzenes and glycols is re-
ported. The process utilizes the carbonyl by-product of the initial dioxomolybdenum(VI)-catalyzed reduction of nitroaromatics with
glycols as a reagent for the imine generation. This method represents the first sustainable domino reaction for the preparation of
biologically relevant heterocycles that internally incorporates the waste formed in the first step to the final product.

Nitroaromatics are readily available, abundant and inexpensive nitrogen sources, ${ }^{1}$ which are typically reduced to the corresponding anilines as the initial step for accessing elaborated nitrogenated compounds. Nevertheless, the direct use of nitroarenes as starting materials, avoiding their prior reduction, is highly desirable for preparing value added nitrogencontaining products in one-pot tandem reactions. ${ }^{2}$ In this field, the straight production of aza-heterocycles from nitrobenzene precursors has recently emerged as a powerful and highly efficient synthetic tool. ${ }^{3}$

Also in the context of the development of sustainable synthetic methods, a highly interesting, although under-explored, approach consists in the fine-tuning of "one-pot" tandem reactions. Accordingly, the by-product generated in the first step of the sequence could be advantageously employed, as a reagent or catalyst, for the following one. In the development of this strategy, pioneered by Shibasaki ${ }^{4}$ and Zhou, ${ }^{5}$ most of the few reported examples are by-product-catalyzed reactions, i.e. processes in which the waste from one reaction catalyzes or modulates a subsequent step in one-pot reaction sequences. ${ }^{6}$ Although some examples have been described in which a waste generated in a first step of a given reaction is recycled and employed as an essential reagent to facilitate the following step, ${ }^{7}$ to the best of our knowledge, no precedent details the reuse of a by-product as a reagent, which ultimately is embodied into the final product.

Following our interest in the development of clean and efficient synthetic methodologies involving redox processes by using non-toxic and easily available dioxomolybdenum(VI) complexes as catalysts, ${ }^{8}$ we have previously reported that nitrobenzenes could be efficiently reduced using pinacol as an oxygen-acceptor that releases acetone and water as the only by-products. ${ }^{9}$ In addition, we have also demonstrated that a variety of glycols could be oxidatively cleaved with DMSO (Scheme 1). ${ }^{10}$

Scheme 1. Our Previous Work on Dioxomolybenum(VI)Catalyzed Reactions, and Proposed Sequence for the Synthesis of Polyheterocycles (this Work).
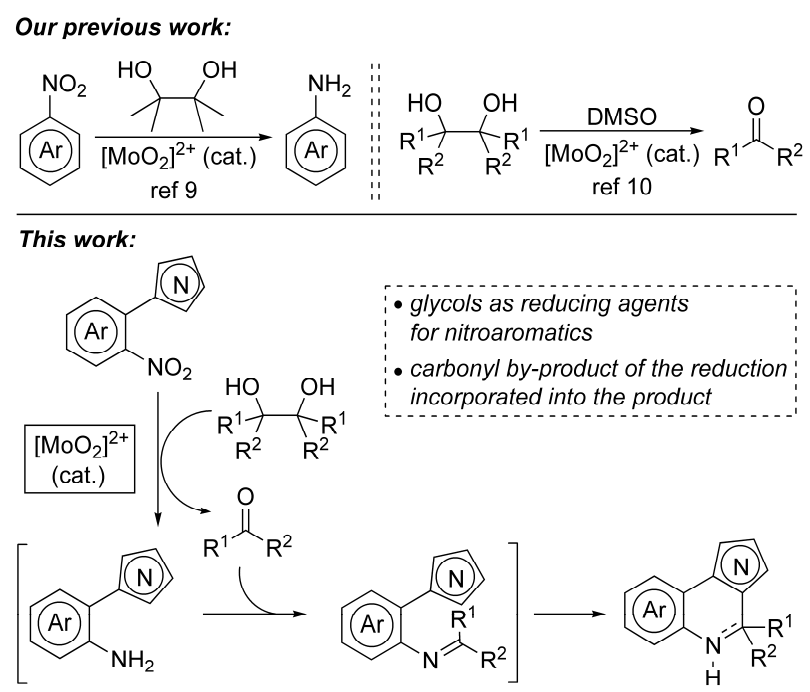
At this point, we envisaged a new tandem sequence for the synthesis of aza-polyheterocycles triggered by our Mocatalyzed reduction method of nitrobenzenes using pinacol, and potentially other glycols, as reducing agents. We also thought that the synthetic efficiency could be significantly improved by recycling the carbonyl by-product of the upstream reduction step, a carbonyl compound, as a reagent for the imine formation step, thus, incorporating it in the tandem reaction (Scheme 1). Herein, we report our results exploiting this concept that allows the preparation of a wide variety of interesting $N$-heterocycles from nitroaromatics.

With these goals in mind, we selected commercially or readily available 1-(2-nitrophenyl) pyrrole $\mathbf{1 a}$ and 1,2diphenylethanediol 2a as model substrates for testing our initial hypothesis (Table 1). After some experimentation, ${ }^{11}$ and based on the conditions we had previously developed for the Mo-catalyzed reduction of nitroarenes with pinacol, ${ }^{9}$ we found that the treatment of 1a with 2a (2.2 equiv) in the presence of a catalytic amount of a dioxomolybdenum(VI) complex, in DMA as solvent and under microwave irradiation at $180{ }^{\circ} \mathrm{C}$, led to a mixture of the desired pyrroloquinoxaline 3aa and its dihydro derivative 4aa, proving our proposed concept (entry 1). Although the increase of reaction time or catalyst loading gave rise to higher 3aa/4aa ratios (entries 2-3), gratifyingly, we found that the addition of a sub-stoichiometric amount of a simple Brønsted acid like PTSA favoured the oxidation of 4aa to 3aa leading to the selective formation of pyrrolo[1,2a]quinoxaline 3aa, which was isolated in $78 \%$ yield (entry 4 ). Although the cooperative effect between the dioxomolybenum(VI) catalyst and PTSA provides enhanced rates in the tandem process reduction/imine formation/cyclization/oxidation, the role of the added Brønsted acid is not crucial for the overall transformation. As previously well-established for several Pictet-Spengler reactions, ${ }^{12}$ its function could be either to favour the cyclization or the oxidation step. In addition, the reaction could also be performed under conventional heating with only slightly lower yields, although an extra catalyst loading and longer reaction times were required (entry 5).

\section{Table 1. Preliminary results ${ }^{a}$}

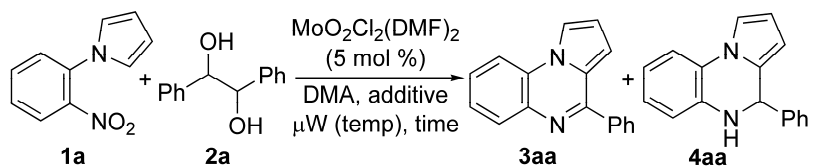

$\begin{array}{lllll}\text { entry } & \text { temp }\left({ }^{\circ} \mathrm{C}\right) & \text { time }(\mathrm{min}) & \text { additive } & \begin{array}{l}\text { 3aa / 4aa } \\ \text { ratio }^{b}\end{array} \\ 1 & 180 & 30 & - & 1.3 / 1 \\ 2 & 180 & 60 & - & 4 / 1 \\ 3 & 180 & 30 & \text { cat. }(20 \mathrm{~mol} \%) & 6 / 1 \\ 4 & 180 & 20 & \text { PTSA (50 mol \%) } & 1 / 0 \\ 5^{c} & 170 & 180 & \text { PTSA (50 mol \%) } & 1 / 0\end{array}$

${ }^{a}$ Reactions were conducted with 1a $(0.25 \mathrm{mmol})$ and 2a $(0.55$ mmol) in DMA $(0.5 \mathrm{~mL})$ under microwave irradiation unless otherwise stated. ${ }^{b}$ Determined by ${ }^{1} \mathrm{H}$ NMR. Complete conversion was observed in all the cases. ${ }^{c}$ Reaction performed under conventional heating, with an additional load of catalyst (5 mol \%).
It should be noted that pyrrolo- and indolo-quinoxalines are quite interesting heterocyclic compounds possessing a wide range of biological activities. ${ }^{13}$ For their construction from pyrrole or indole derivatives, the Pictet-Spengler and BischlerNapieralski reactions are the most extensively used approaches, starting from 1-(2-aminophenyl) pyrroles or indoles. ${ }^{14}$ Recent efforts in the field have been devoted to the replacement of the carbonyl counterpart by other reagents. ${ }^{15}$ Taking into account that most of the reported methods for the synthesis of these $N$-heterocycles use anilines as starting materials, and the fact that these aniline derivatives are typically prepared by reduction of their nitroaromatic precursors, the development of methods for using nitroarenes as starting materials in one-pot processes represents a challenge in the field. ${ }^{16}$

The next goal was to evaluate the scope of the new method (Table 2). In a first set of experiments, the structure of the glycol 2 was varied. Functionalized secondary glycols $\mathbf{2 b - d}$ were reacted with model pyrrole derivative 1a leading to the corresponding pyrroloquinoxalines 3ab-ad in good to high yields (entries 2-4). Moreover, tertiary glycols 2e-g also participate in this tandem reaction and react with 1a under the same optimized conditions. In these cases, dihydropyrrolo[1,2a]quinoxalines 4 were obtained due to the generation of a ketone as byproduct in the initial reduction of $1 \mathbf{a}$ with the tertiary glycol (entries 5-7). ${ }^{17}$ Then, the functional group tolerance in nitroaromatic $\mathbf{1}$ was evaluated using pyrrole derivatives $\mathbf{1 b}-\mathbf{d}$, ${ }^{11}$ bearing chlorine or methoxy groups at different positions, by their treatment with any of the glycols 2a-e (entries 8-13). Remarkably, this tandem process works nicely in most of the examined examples providing the final (dihydro)pyrrolo[1,2-a]quinoxalines $\mathbf{3}$ and $\mathbf{4}$ in good to high yields.

Table 2. Reactions of 1-(2-Nitrophenyl)pyrroles 1 with 1,2diols 2 . Synthesis of 3 and $4^{a}$
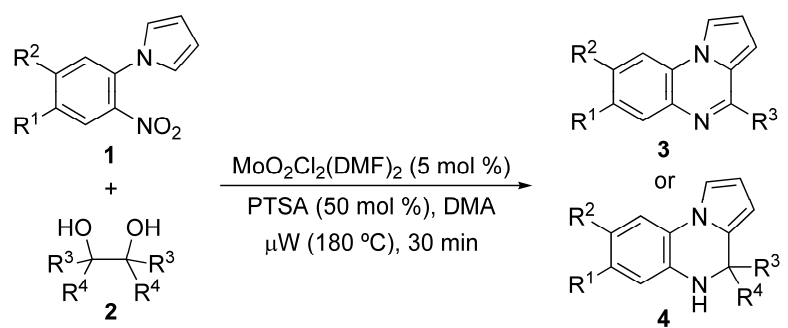

$\begin{array}{lllllllll}\text { entry } \mathbf{1} & \mathrm{R}^{1} & \mathrm{R}^{2} & \mathbf{2} & \mathrm{R}^{3} & \mathrm{R}^{4} & \text { product } & \text { yield } \\ 1 & \mathbf{1 a} & \mathrm{H} & \mathrm{H} & \mathbf{2 a} & \mathrm{Ph} & \mathrm{H} & \text { 3aa } & 78(73)^{c} \\ 2 & \mathbf{1 a} & \mathrm{H} & \mathrm{H} & \mathbf{2 b} & 4-\mathrm{ClC}_{6} \mathrm{H}_{4} & \mathrm{H} & \text { 3ab } & 70 \\ 3 & \mathbf{1 a} & \mathrm{H} & \mathrm{H} & \mathbf{2 c} & 4-\mathrm{MeOC}_{6} \mathrm{H}_{4} \mathrm{H} & \text { 3ac } & 71 \\ 4 & \mathbf{1 a} & \mathrm{H} & \mathrm{H} & \mathbf{2 d} & 4-\mathrm{BrC}_{6} \mathrm{H}_{4} & \mathrm{H} & \text { 3ad } & 83 \\ 5 & \mathbf{1 a} & \mathrm{H} & \mathrm{H} & \mathbf{2 e} & \mathrm{Me} & \mathrm{Me} & \text { 4ae } & 94 \\ 6 & \mathbf{1 a} & \mathrm{H} & \mathrm{H} & \mathbf{2 f} & \mathrm{Ph} & \mathrm{Me} & \mathbf{4 a f} & 78 \\ 7 & \mathbf{1 a} & \mathrm{H} & \mathrm{H} & \mathbf{2 g} & \mathrm{Ph} & \mathrm{Ph} & \text { 4ag } & 60 \\ 8 & \mathbf{1 b} & \mathrm{Cl} & \mathrm{H} & \mathbf{2 a} & \mathrm{Ph} & \mathrm{H} & \text { 3ba } & 80 \\ 9 & \mathbf{1 b} & \mathrm{Cl} & \mathrm{H} & \mathbf{2 e} & \mathrm{Me} & \mathrm{Me} & \text { 4be } & 76 \\ 10 & \mathbf{1 c} & \mathrm{H} & \mathrm{Cl} & \mathbf{2 a} & \mathrm{Ph} & \mathrm{H} & \text { 3ca } & 81\end{array}$




$\begin{array}{lllllllll}11 & \text { 1c } & \mathrm{H} & \mathrm{Cl} & \text { 2c } & 4-\mathrm{MeOC}_{6} \mathrm{H}_{4} \mathrm{H} & \text { 3cc } & 84 \\ 12 & \text { 1d } & \mathrm{MeO} & \mathrm{H} & \text { 2d } & 4-\mathrm{BrC}_{6} \mathrm{H}_{4} & \mathrm{H} & \text { 3dd } & 70 \\ 13 & \text { 1d } & \mathrm{MeO} & \mathrm{H} & \text { 2e } & \mathrm{Me} & \mathrm{Me} & \text { 4de } & 72\end{array}$

${ }^{a}$ All reactions were conducted with $0.5 \mathrm{mmol}$ of nitroarene derivative 1 and $1.1 \mathrm{mmol}$ of glycol 2 in DMA $(1 \mathrm{~mL})$ under microwave irradiation (maximum wattage $150 \mathrm{~W}$; see Supporting Information for details). ${ }^{b}$ Isolated yield based on the starting nitroaromatic 1. ${ }^{c}$ Carried out under conventional heating at 170-180 ${ }^{\circ} \mathrm{C}$ for $3 \mathrm{~h}$ (an additional $5 \mathrm{~mol} \%$ of the catalyst was added after $1 \mathrm{~h}$ ).

Due to the interest of functionalized ullazines (indolizino[6,5,4,3-aij]quinolines) in optoelectronics applications, a few approaches have been developed for their syntheses. ${ }^{18}$ In this context, Langer and co-workers have reported the first preparation, as well as the physical properties of azaullazines, ${ }^{19}$ whereas the only synthesis of related triazacyclopenta[c,d]phenalenes (diaza-ullazines) was reported by Balli in $1992 .{ }^{20}$ So, we proposed to apply our methodology to access this type of interesting heterocycles. Thus, treatment of 1-(2,6-dinitrophenyl)pyrrole 1e with glycol 2a gave rise to the 3,9-diphenyl-substituted diaza-ullazine 5 in $50 \%$ yield (Scheme 2). Remarkably, the previous preparation of this compound reported by Balli from the same 1e was performed in three independent steps with an overall $14 \%$ yield. ${ }^{20}$

\section{Scheme 2. Synthesis of Diaza-ullazine 5}

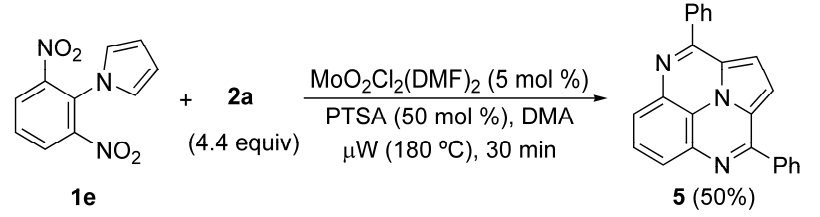

In an analogous way, the reaction of 1-(2nitrophenyl)indoles 6 with a selection of secondary glycols 2a,c enabled facile access to related indolo[1,2-a]quinoxalines $\mathbf{7}$, whereas reaction employing a tertiary glycol like $\mathbf{2 f}$ afforded the corresponding dihydroindolo[1,2-a]quinoxaline $\mathbf{8}$ (Scheme 3). Interestingly, a trifluoromethyl group does not interfere in the outcome of the reaction as shown with the preparation of $\mathbf{7 b a}$. Again, we demonstrated that the process could be also performed under conventional heating (170-180 ${ }^{\circ} \mathrm{C}, 3 \mathrm{~h}$ ), and in this way 7 aa was isolated in $83 \%$ yield.

Scheme 3. Preparation of Indolo[1,2-a]quinoxalines 7 and Dihydroindolo[1,2-a]quinoxaline 8af

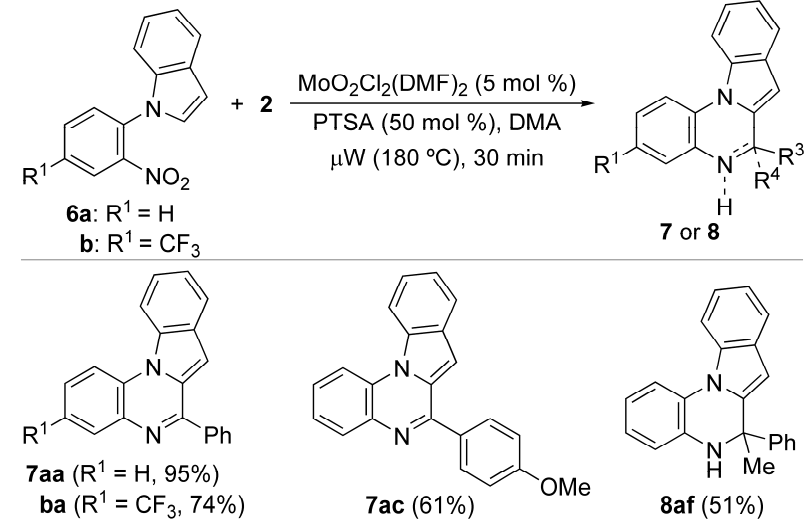

At this point, we tried to extend the scope of this strategy for the direct synthesis of aza-heterocycles from nitroarenes to the preparation of pyrrolo- and indolo[3,2-c]quinolines. These heterocycle cores are present in natural alkaloids and several analogues with a wide spectrum of relevant biological or pharmacological properties. $^{21}$ Although there have been reported different syntheses for these heterocyclic derivatives, ${ }^{22}$ most of them required expensive or multi-step preparation of starting materials, and displayed limited substrate scope or lack of functional group tolerance. Based on our previous results we proposed easily prepared 2-(2-nitrophenyl)pyrroles and indoles 9 as starting materials. ${ }^{11}$ Thus, their treatment with a variety of secondary glycols 2 , under similar reaction conditions as described for the synthesis of quinoxalines $\mathbf{3}$ and $\mathbf{7}$, afforded high yields of the intended pyrrolo and indoloquinolines 10 (Scheme 4). In addition, using tertiary glycols 2e,f dihydroquinoline derivatives $\mathbf{1 1}$ could also be obtained. ${ }^{23}$ The reported examples also show the usefulness of glycols possessing substituents at the ortho-position (2h), as well as that there is no need to protect the nitrogen atom of the starting nitroarene, thus allowing the synthesis of $N-\mathrm{H}$ heterocycles (Scheme 4). In addition, indoloquinoline 10ca was also synthesized under conventional heating and isolated in $78 \%$ yield. Interestingly, the reactions of starting pyrrole derivatives 9a,b took place without the addition of the Brønsted acid, further proving that this cascade sequence could be catalyzed exclusively by the molybdenum complex with highly reactive substrates.

Scheme 4. Synthesis of Pyrrolo- and Indolo[3,2-c]quinoline Derivatives 10 and 11 from 2-(2-Nitrophenyl)pyrroles and Indoles 9a-c 
(lil'

9a: $R^{1}=\mathrm{Me}$ (pyrrolyl)

b: $\mathrm{R}^{1}=\mathrm{H}$ (pyrrolyl)

c: $\mathrm{R}^{1}=\mathrm{H}$ (indolyl)

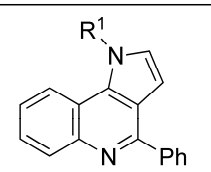

10aa $\left(R^{1}=\mathrm{Me}, 72 \%\right)$

ba $\left(R^{1}=H, 69 \%\right)$

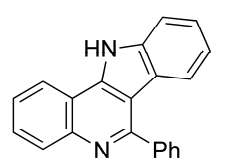

$10 \mathrm{ca}(83 \%)$
$\frac{\mathrm{MoO}_{2} \mathrm{Cl}_{2}(\mathrm{DMF})_{2}(5 \mathrm{~mol} \%)}{\mathrm{DMA}, \mu \mathrm{W}\left(180^{\circ} \mathrm{C}\right), 30 \mathrm{~min}}$ PTSA $(25 \mathrm{~mol} \%)$ for $9 \mathrm{c}$

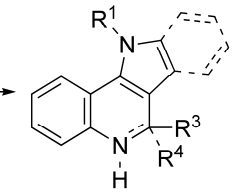

10 or 11

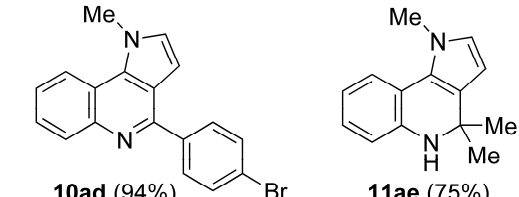

10ad $(94 \%)$

11ae $(75 \%)$
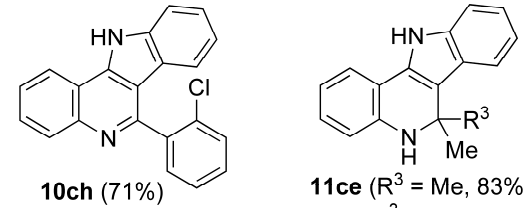

11ce $\left(R^{3}=M e, 83 \%\right.$ cf $\left(\mathrm{R}^{3}=\mathrm{Ph}, 65 \%\right)$

In summary, we have shown that dioxomolybdenum(VI) complexes are able to catalyze the formation of a wide variety of pyrrolo- and indolo-fused quinoxalines and quinolines using easily available nitroarenes as the nitrogen source and glycols as the carbonyl source and reducing agents. The nitro reduction, imine generation, annulation with heterocycle formation, and final oxidation occurred in a new domino process that involves the incorporation of the carbonyl reduction byproduct into the final aza-heterocycle. Remarkably, this is the first report in which the waste by-product of a reaction has been used as a reactant for the next step and included into the final product, thus enhancing the overall atom economy of the process. This strategy offers an economic and clean method for the one-pot synthesis of these $N$-heterocycles, frequently found in biological active compounds, from nitroaromatics.

\section{ASSOCIATED CONTENT}

\section{Supporting Information}

Full experimental procedures, characterization data, and copies of NMR spectra. This material is available free of charge via the Internet at http://pubs.acs.org.

\section{AUTHOR INFORMATION}

\section{Corresponding Author}

*E-mail: rsd@ubu.es

\section{Notes}

The authors declare no competing interest.

\section{ACKNOWLEDGMENT}

We are grateful to the Junta de Castilla y León and FEDER (BU076U16) and Ministerio de Economía y Competitividad (MINECO) (CTQ2015-70371-REDT and CTQ2016-75023-C2-1P) for financial support. R.R.-P. thanks Universidad de Burgos for a pre-doctoral contract.

\section{REFERENCES}

(1) Ono, N. The Nitro Group in Organic Synthesis, Wiley-VCH: New York, 2001.

(2) N-Alkylated amines: (a) Gui, J.; Pan, C.-M.; Jin, Y.; Qin, T.; Lo, J. C.; Lee, B. J.; Spergel, S. H.; Mertzman, M. E.; Pitts, W. J.; La
Cruz, T. E.; Schmidt, M. A.; Darvatkar, N.; Natarajan, S. R.; Baran, P. S. Science 2015, 348, 886-891. Imines: (b) Zhang, B.; Guo, X.-W.; Liang, H.; Ge, H.; Gu, X.; Chen, S.; Yang, H.; Qin, Y. ACS Catal. 2016, 6, 6560-6566. Amides: (c) Zhan, W.; Xie, J.; Rao, B.; Luo, M. J. Org. Chem. 2015, 80, 3504-3511. (d) Zhou, F.; Wang, D.-S.; Guan, X.; Driver, T. G. Angew. Chem. Int. Ed. 2017, 56, 4530-4534.

(3) (a) He, L.; Wang, J.-Q.; Gong, Y.; Liu, Y.-M.; Cao, Y.; He, H.Y.; Fan, K.-N. Angew. Chem. Int. Ed. 2011, 50, 10216-10220. (b) Wu, M.; Hu, X.; Liu, J.; Liao, Y.; Deng, G.-J. Org. Lett. 2012, 14, 2722-2725. (c) Tang, L.; Guo, X.; Yang, Y.; Zha, Z.; Wang, Z. Chem. Commun. 2014, 50, 6145-6148. (d) Nguyen, T. B.; Ermolenko, L.; Retailleau, P.; Al-Mourabit, A. Angew. Chem. Int. Ed. 2014, 53, 13808-13812. (e) Imrich, H.-G.; Conrad, J.; Bubrin, D.; Beifuss, U. J. Org. Chem. 2015, 80, 2319-2332.

(4) Kinoshita, T.; Okada, S.; Park, S.-R.; Matsunaga, S.; Shibasaki, M. Angew. Chem. Int. Ed. 2003, 42, 4680-4684.

(5) Cao, J.-J.; Zhou, F.; Zhou, J. Angew. Chem. Int. Ed. 2010, 49, 4976-4980.

(6) For selected examples, see: (a) Yang, B.-L.; Weng, Z.-T; Yang, S.-J.; Tian, S.-K. Chem. Eur. J. 2010, 16, 718-723. (b) Gao, M.; Yang, Y.; Wu, Y.-D.; Deng, C.; Shu, W.-M.; Zhang, D.-X.; Cao, L.-P.; She, N.-F.; Wu, A.-X. Org. Lett. 2010, 12, 4026-4029. (c) Lu, J.; Toy, P. H. Chem. Asian J. 2011, 6, 2251-2254. (d) Te, Y.; Lu, J.; Toy, P. H. Chem. Asian J. 2012, 7, 351-359. (e) Chen, L.; Shi, T.-D.; Zhou, J. Chem. Asian J. 2013, 8, 556-559. (f) Chen, L.; Du, Y.; Zeng, X.-P.; Shi, T.-D.; Zhou, F.; Zhou, J. Org. Lett. 2015, 17, 1557-1560. (g) Zeng, X.-P.; Cao, Z.-Y.; Wang, X.; Chen, L.; Zhou, F.; Zhu, F.; Wang, C.-H.; Zhou, J. J. Am. Chem. Soc. 2016, 138, 416-425. (h) Pace, V.; Castoldi, L.; Mazzeo, E.; Rui, M.; Langer, T.; Holzer, W. Angew. Chem. Int. Ed. 2017, doi: 10.1002/anie.201706236. (i) For an excellent review, see: Zhou, J.; Zeng, X.-P. In Multicatalyst System in Asymmetric Catalysis; Zhou, J., Ed.; John Wiley \& Sons: New York, 2014; Ch. 9, pp 633-670.

(7) (a) Zhu, F.; Xu, P.-W.; Zhou, F.; Wang, C.-H.; Zhou, J. Org. Lett. 2015, 17, 972-975. (b) Bodero, O.; Spivey, A. C. Synlett 2017, $28,471-474$.

(8) (a) Sanz, R.; Escribano, J.; Aguado, R.; Pedrosa, M. R.; Arnáiz, F. J. Adv. Synth. Catal. 2007, 349, 313-318. (b) García N.; GarcíaGarcía, P.; Fernández-Rodríguez, M. A.; García, D.; Pedrosa, M. R.; Arnáiz, F. J.; Sanz, R. Green Chem. 2013, 15, 999-1005. (c) García, N.; Fernández-Rodríguez, M. A.; García-García, P.; Pedrosa, M. R.; Arnáiz, F. J.; Sanz, R. RSC Adv. 2016, 6, 27083-27086. For a review, see: (d) Sanz, R.; Pedrosa, M. R. Curr. Org. Synth. 2009, 6, 239-263.

(9) (a) García N.; García-García, P.; Fernández-Rodríguez, M. A.; Rubio, R.; Pedrosa, M. R.; Arnáiz, F. J.; Sanz, R. Adv. Synth. Catal. 2012, 354, 321-327. More recently we have updated this methodology to the deoxygenation of $\mathrm{N}$-oxides and $\mathrm{N}$-hydroxybenzotriazoles: (b) Rubio-Presa, R.; Fernández-Rodríguez, M. A.; Pedrosa, M. R.; Arnáiz, F. J.; Sanz, R. Adv. Synth. Catal. 2017, 359, 1752-1757.

(10) García, N.; Rubio-Presa, R.; García-García, P.; FernándezRodríguez, M. A.; Pedrosa, M. R.; Arnáiz, F. J.; Sanz, R. Green Chem. 2016, 18, 2335-2340.

(11) See Supporting Information for further details.

(12) Kamal, A.; Babu, K. S.; Kovvuri, J.; Manasa, V.; Ravikumar, A.; Alarifi, A. Tetrahedron Lett. 2015, 56, 7012-7015.

(13) See, for instance: Lv, W.; Budke, B.; Pawlowski, M.; Connell, P. P.; Kozikowski, A. P. J. Med. Chem. 2016, 59, 4511-4525.

(14) See, for instance: (a) Preetam, A.; Nath, M. RSC Adv. 2015, 5, 21843-21853. (b) Wang, C.; Li, Y.; Zhao, J.; Cheng, B.; Wang, H.; Zhai, H. Tetrahedron Lett. 2016, 57, 3908-3911. For pioneering work, see: (c) Cheeseman, G. W. H.; Tuck, B. J. Chem. Soc. C, 1966, 852-855.

(15) Bencylamines: (a) Ramamohan, M.; Sridhar, R.; Raghavendrarao, K.; Paradesi, N.; Chandrasekhar, K. B.; Jayaprakash, S. Synlett 2015, 26, 1096-1100. 1,3-Dicarbonyls: (b) Xie, C.; Feng, L.; Li, W.; Ma, X.; Ma, X.; Liu, Y.; Ma, C. Org. Biomol. Chem. 2016, 14, 8529-8535. Alcohols: (c) Li, J.; Zhang, J.; Yan, H.; Gao, Z.; Jiang, G. J. Org. Chem. 2017, 82, 765-769. DMSO: (d) Xie, C.; 
Zhang, Z.; Li, D.; Gong, J.; Han, X.; Liu, X.; Ma, C. J. Org. Chem. 2017, 82, 3491-3499.

(16) Only one example is known for the one-pot preparation of pyrrolo[1,2-a]quinoxalines from 1-(2-nitrophenyl) pyrroles and alcohols. Disappointingly, it suffers from severe drawbacks such as the use of a large excess of iron powder, $\mathrm{HCl}$, and mainly the alcohol, that only allows the use of simple short-chain aliphatic alcohol counterparts. See: M. F. Pereira, V. Thiéry, Org. Lett. 2012, 14, 4754-4757.

(17) For the synthesis of dihydropyrrolo[1,2-a]quinoxalines, see: Shinde, V. S.; Mane, M. V.; Vanka, K.; Mallick, A.; Patil, N. T. Chem. Eur. J. 2015, 21, 975-979, and references cited therein.

(18) See, for instance: (a) Delcamp, J. H.; Yella, A.; Holcombe, T. W.; Nazeeruddin, M. K.; Grätzel M. Angew. Chem. Int. Ed. 2013, 52,
376-380. (b) Das, A.; Ghosh, I.; König, B. Chem. Commun. 2016, 52 8695-8698.

(19) Boldt, S.; Parpart, S.; Villinger, A.; Ehlers, P.; Langer, P. Angew. Chem. Int. Ed. 2017, 56, 4575-4578.

(20) Hou, D.; Balli, H. Helv. Chim. Acta 1992, 75, 2608-2612.

(21) See, for instance: Wang, N.; Wicht, K. J.; Imai, K.; Wang, M.q.; Ngoc. T. A.; Kiguchi, R.; Kaiser, M.; Egan, T. J.; Inokuchi, T. Bioorg. Med. Chem. 2014, 22, 2629-2642.

(22) For recent examples, see: (a) Guo, S.; Tao, L.; Zhang, W. Zhang, X.; Fan, X. J. Org. Chem. 2015, 80, 10955-10964. (b) Zheng, C.; Liu, T.; Liu, X.; Fan, X.; Wu, J. J. Org. Chem. 2016, 81, 9428-9432.

(23) Patil, N. T.; Kavthe, R. D.; Shinde, V. S.; Sridhar, B. J. Org. Chem. 2010, 75, 3371-3380. 